\title{
Sarah Alyn Stacey, Marc-Claude de Buttet (1529/31-1586). L'honneur de la Savoie
}

\section{Michele Mastroianni}

\section{Q OpenEdition \\ 1 Journals}

\section{Edizione digitale}

URL: http://journals.openedition.org/studifrancesi/8868

DOI: ERREUR PDO dans /localdata/www-bin/Core/Core/Db/Db.class.php L.34 : SQLSTATE[HY000]

[2006] MySQL server has gone away

ISSN: 2421-5856

\section{Editore}

Rosenberg \& Sellier

\section{Edizione cartacea}

Data di pubblicazione: 1 octobre 2008

Paginazione: 443

ISSN: 0039-2944

\section{Notizia bibliografica digitale}

Michele Mastroianni, «Sarah Alyn Stacey, Marc-Claude de Buttet (1529/31-1586). L'honneur de la Savoie», Studi Francesi [Online], 155 (LII | II) | 2008, online dal 30 novembre 2015, consultato il 07 janvier 2021. URL: http://journals.openedition.org/studifrancesi/8868 ; DOI: https://doi.org/ERREUR PDO dans / localdata/www-bin/Core/Core/Db/Db.class.php L.34 : SQLSTATE[HY000] [2006] MySQL server has gone away

Questo documento è stato generato automaticamente il 7 janvier 2021.

\section{(c)}

Studi Francesi è distribuita con Licenza Creative Commons Attribuzione - Non commerciale - Non opere derivate 4.0 Internazionale. 


\title{
Sarah Alyn Stacey, Marc-Claude de Buttet (1529/31-1586). L'honneur de la Savoie
}

\author{
Michele Mastroianni
}

\section{NOTIZIA}

SARAH ALYN STACEY, Marc-Claude de Buttet (1529/31-1586). L'honneur de la Savoie, Paris, Champion, 2006 («Études et essais sur la Renaissance», LXX), pp. 235.

1 S. Alyn Stacey aveva già procurato una pregevole edizione dell'ultima grande opera di Claude Buttet, L'Amalthée del 1575 (Paris, Champion, 2003: cfr. questi «Studi», 145, 2005, p. 148). Ora, su questo poeta savoiardo, su cui negli ultimi decenni ha attirato l'attenzione Louis Terreaux, ma rimasto ingiustamente figura marginale negli studi dei cinquecentisti, la stessa Alyn Stacey ci offre una interessante monografia d'insieme che, basandosi anche su un accurato spoglio archivistico a Parigi, a Chambéry, ad Annecy, a Torino e a Ginevra, fa il punto riguardo alle ricerche su Buttet, autore ai suoi tempi celebrato come l'honneur de la Savoye (edizione e monografia costituivano una tesi di dottorato discussa all'Università di Hull, nel 1992). Il lavoro ripercorre accuratamente la vita di Buttet, scandendone le tappe dalla Savoia a Parigi (ove è in rapporto con la corte), di nuovo alla Savoia fino alla morte avvenuta a Ginevra nel 1586. Nella seconda parte ricostruisce i rapporti culturalmente significativi. In particolare, i rapporti con il gruppo della Pléiade, da cui Buttet fu manifestamente influenzato (ritroviamo, citati dal savoiardo o che lo citano, Ronsard, Daurat, Des Autelz, Baif, Du Bellay, Belleau, Jodelle), o con altri autori dell'epoca, quali Peletier du Mans, Grévin, d'Espinay, Chappuys, La Meschinière (Pierre Enoch), La Jessée, Du Chesne, Bèze, Boyssonné, Bertrand. Interessante e utile è la repertoriazione degli amici savoiardi (fra cui Antoine Baptendier, Claude e Jean-Gaspard Lambert, Jean de Balme, Emmanuel-Philibert de Pingon, Louis Milliet, Jehan de Piochet, Amé Du Coudray, Jean Bordat), nomi, accompagnati da puntuali riferimenti archivistici, che permettono di ricostruire - o 
perlomeno di porre le basi per ricostruire - un panorama della vita intellettuale savoiarda nel Cinquecento. Importante è la bibliografia e la repertoriazione archivistica. 